PREPARED FOR THE U.S. DEPARTMENT OF ENERGY, UNDER CONTRACT DE-AC02-76CH03073

PPPL-3604

PPPL-3604

UC-70

Tritium Issues in Next Step Devices

by

C.H. Skinner and G. Federici

September 2001

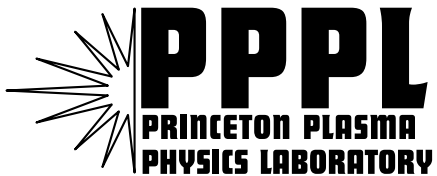

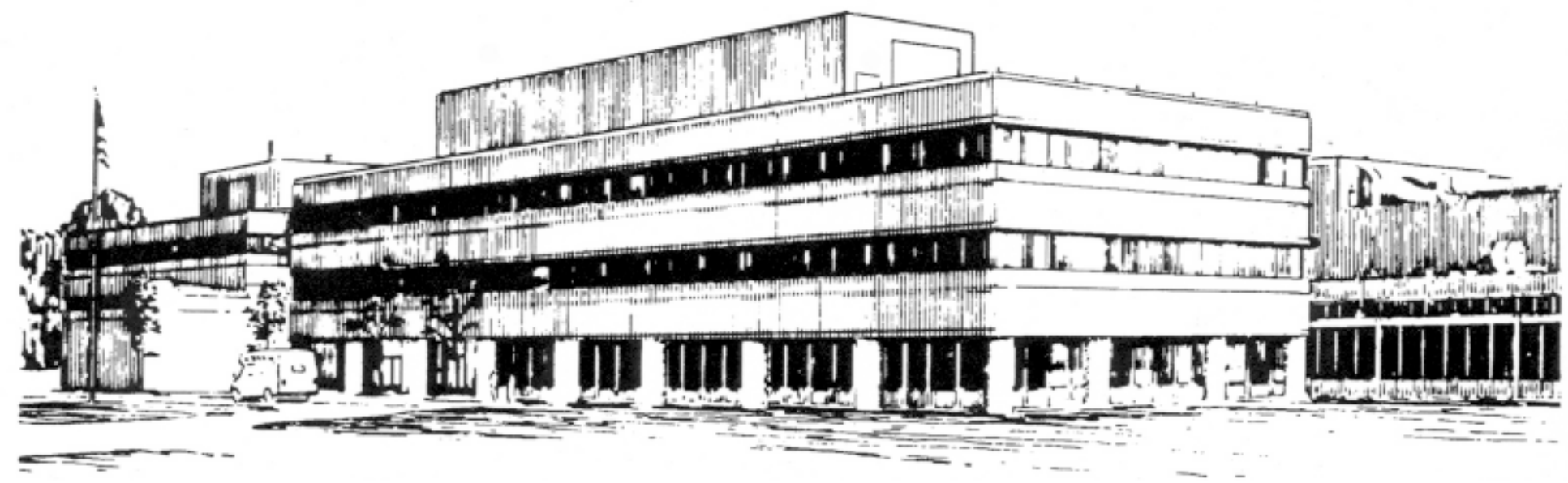

PRINCETON PLASMA PHYSICS LABORATORY PRINCETON UNIVERSITY, PRINCETON, NEW JERSEY 


\section{PPPL Reports Disclaimer}

This report was prepared as an account of work sponsored by an agency of the United States Government. Neither the United States Government nor any agency thereof, nor any of their employees, makes any warranty, express or implied, or assumes any legal liability or responsibility for the accuracy, completeness, or usefulness of any information, apparatus, product, or process disclosed, or represents that its use would not infringe privately owned rights. Reference herein to any specific commercial product, process, or service by trade name, trademark, manufacturer, or otherwise, does not necessarily constitute or imply its endorsement, recommendation, or favoring by the United States Government or any agency thereof. The views and opinions of authors expressed herein do not necessarily state or reflect those of the United States Government or any agency thereof.

\section{Availability}

This report is posted on the U.S. Department of Energy's Princeton Plasma Physics Laboratory Publications and Reports web site in Calendar Year 2001. The home page for PPPL Reports and Publications is: http://www.pppl.gov/pub_report/

DOE and DOE Contractors can obtain copies of this report from:

U.S. Department of Energy

Office of Scientific and Technical Information

DOE Technical Information Services (DTIS)

P.O. Box 62

Oak Ridge, TN 37831

Telephone: (865) 576-8401

Fax: (865) 576-5728

Email: reports@adonis.osti.gov

This report is available to the general public from:

National Technical Information Service

U.S. Department of Commerce

5285 Port Royal Road

Springfield, VA 22161

Telephone: 1-800-553-6847 or

(703) 605-6000

Fax: (703) 321-8547

Internet: http://www.ntis.gov/ordering.htm 
International Conference on Advanced Diagnostics for Magnetic and Interial Fusion, Varenna, Italy, Sept 3-7, 2001.

\title{
TRITIUM ISSUES IN NEXT STEP DEVICES
}

\author{
C. H. Skinner and G. Federici*
}

\section{INTRODUCTION}

Tritium issues will play a central role in the performance and operation of next-step deuterium-tritium (DT) burning tokamaks and the safety aspects associated with tritium will attract intense public scrutiny. Tritium fuel has been successfully used in the Tokamak Fusion Test Reactor (TFTR) and the Joint European Torus (JET) producing 10 and $16 \mathrm{MW}$ of fusion power respectively[1,2]. This experience together with focussed laboratory studies, has illuminated the challenges[3]. The orders-of-magnitude increase in duty cycle and stored energy will be a much larger change than the increase in plasma performance necessary to achieve high fusion gain and ignition[4,5]. Erosion of plasma facing components will scale up with the pulse length from being barely measurable on existing machines to cm-scale. Magnetic Fusion Energy (MFE) devices with carbon plasma facing components will accumulate tritium by co-deposition with the eroded carbon and this will strongly constrain plasma operations. We report on a novel laser-based method to remove codeposited tritium from carbon plasma facing components in tokamaks. The operational lifetime of alternative materials such as tungsten has significant uncertainties due to melt layer loss during disruptions. Production of dust and flakes will need careful monitoring and minimization, and control and accountancy of the tritium inventory will be critical issues. The relevant plasma material interactions are comprehensively reviewed in [4]. Operation of next step experiments will help resolve key tritium issues in the design of a magnetic fusion reactor. Many of the tritium issues in Inertial Fusion Energy (IFE) are similar to MFE, but some, for example those associated with the target factory, are unique to IFE.

The plasma-edge region in a tokamak has greater complexity than the core due to lack of poloidal symmetry and nonlinear feedback between the plasma and wall. Sparse diagnostic coverage and low dedicated experimental run time has hampered the development of predictive models. Diagnostic advances are urgently needed to better characterize the plasma edge and wall and improve our predictive capability.

\footnotetext{
* C.H. Skinner, Princeton Plasma Physics Lab., Princeton N.J. 08543. G. Federici, ITER Garching Joint Work Site, Boltzmannstrasse 2, D-85748 Garching, Germany.
} 

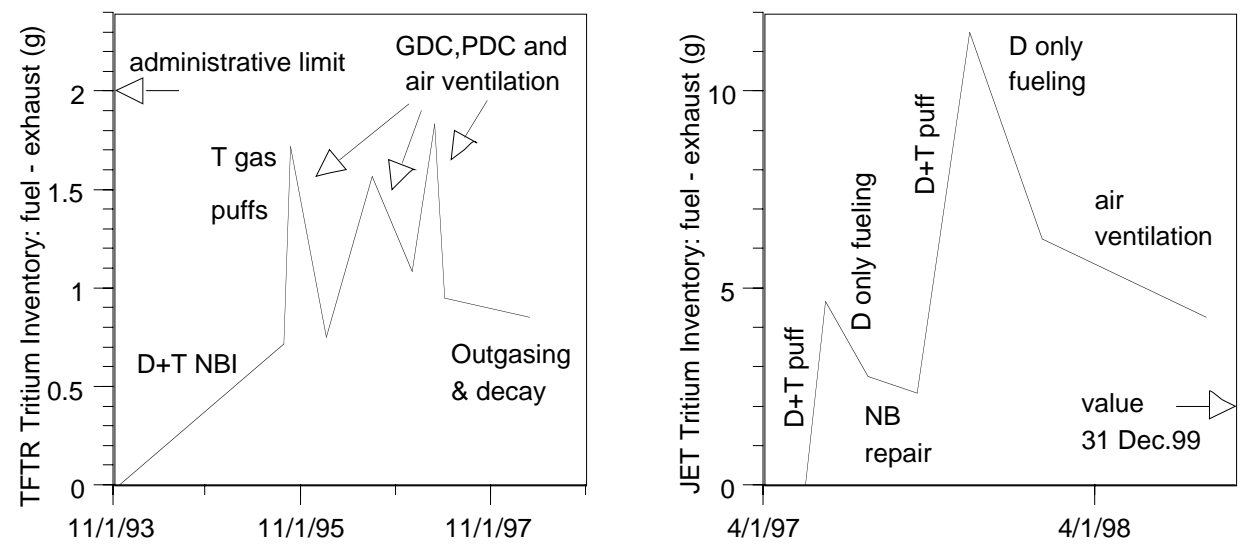

Fig. 1 Tritium Retention on TFTR and JET

\section{TRITIUM EXPERIENCE IN CONTEMPORARY TOKAMAKS}

A large fraction of tritium was retained during DT plasma operations in TFTR and JET [6,7] and a comparison shows striking similarities and contrasts[8]. Tritium was retained by co-deposition with eroded carbon and by isotope exchange with previously retained deuterium (fig. $1 \&$ table 1 ). When the tritium in-vessel inventory approached the administrative safety limit, it was removed by extensive campaigns involving several weeks of glow discharge cleaning and deuterium operation. An unexpectedly large amount of tritium was transported to the JET sub divertor region (sect. 6). In summary, while tritium retention was not a significant limit to plasma operations in these machines, the high rate of tritium retention and slow rate of tritium removal would be unacceptable in a next step device and in a fusion reactor.

Table 1. Tritium Retention in TFTR and JET.

\begin{tabular}{rcc}
\hline & TFTR & JET (DTE1) \\
\hline $\begin{array}{r}\text { Total tritium injected by NBI } \\
\text { Total tritium injected by gas puff }\end{array}$ & $3.1 \mathrm{~g}$ & $0.6 \mathrm{~g}$ \\
Total tritium retained during DT operations & $2.1 \mathrm{~g}$ & $34.4 \mathrm{~g}$ \\
Initial \% retention during T puff fueling & $\approx 90 \%$ & $11.5 \mathrm{~g}$ \\
(wall saturation + isotope exchange) & $\approx 40 \%$ \\
Longer term \% retention including D only fueling & $51 \%$ & $17 \%$ \\
(mostly co-deposition) & \\
Tritium remaining in torus & $0.85 \mathrm{~g}(4 / 98)$ & $4.2 \mathrm{~g}(7 / 98)$ \\
Long term retention & $16 \%(4 / 98)$ & $12 \%(7 / 98)$ \\
Average deuterium retention (for comparison) & $\approx 40 \%$ & $\approx 10-15 \%$ \\
\hline
\end{tabular}


The retention experience of Alcator C-mod is particularly interesting since it is lined with Mo tiles and there are no carbon plasma facing components. Although no external tritium was supplied, nuclear reactions in the deuterium plasma produce tritium and neutrons and the amount of tritium generated was deduced from the measured neutron fluence. The amount of deuterium and tritium retained in the vessel was measured by analysis of tiles removed from the vessel[9]. The analysis showed that most of D inventory was implanted (not codeposited) on main chamber wall. Very sensitive measurements of tritium gave a lower limit for the fractional tritium retention of less than $0.2 \%$. This is encouraging confirmation of the drastically lower in-vessel tritium inventory possible in the absence of carbon plasma facing components.

\section{TRITIUM IN ITER AND FIRE}

Safety issues and fuel economy will be primary drivers in the operation of next step DT machines. Fusion is considered to be 100 to 1000 times less hazardous than fission, non the less public sensitivities are acute[10]. Tritium permeation and leakage during normal operation must be strictly limited. The total tritium inventory on site is restricted to avoid the need for public evacuation under the worst postulated accident. Tritium (as hydrogen) can pose a deflagration or detonation risk. Present guidance from the US Department of Energy for a site with a $1 \mathrm{~km}$ radius, would limit the accidental release of HTO to $15 \mathrm{~g}$ at ground level or $150 \mathrm{~g}$ if elevated[11]. Tritium inventories larger than this will need highly reliable robust confinement barriers. Vacuum penetrations either for diagnostic purposes, or for IFE beams can be problematic.

The availability of fuel is the most fundamental requirement of any power source and independent of safety considerations, the available tritium supply is limited. In the growth of a future DT powered economy, tritium for future reactors will be bred in a lithium blanket but the margin for tritium breeding is relatively low: the tritium breeding ratio for MFE is $1.05-1.18$, and for IFE is $1.05-1.75$ [12]. This factor also limits tritium inventories in a reactor design to approximately $1 \mathrm{~kg}$.

ITER employs a variety of plasma facing materials selected for their suitability to regions of the vessel with different power and particle flux characteristics[4]. The first wall is Be, the baffle regions of the target, the dome and the liner in the private flux region below the dome are $\mathrm{W}$ and the divertor strike-point regions are carbon fiber composite (CFC). CFC is chosen because of its high thermal shock resistance and tolerance to off-normal events, however carbon erosion will facilitate retention of tritium via co-deposition of tritium with carbon. The in-vessel tritium limit is $\sim 350 \mathrm{~g}$ limit and migration of hydrocarbon radicals may result in accumulation of tritium in inaccessible areas (as in JET). The number of plasma pulses before the inventory limit is reached is estimated to be $70-170$ pulses (Fig. 2)[13]. After this, the subsequent availability of the machine for plasma operations will depend on efficient and fast tritium removal techniques that have yet to be fully demonstrated in a tokamak (see sect. 6). For comparison, in TFTR several weeks were needed for tritium removal after 


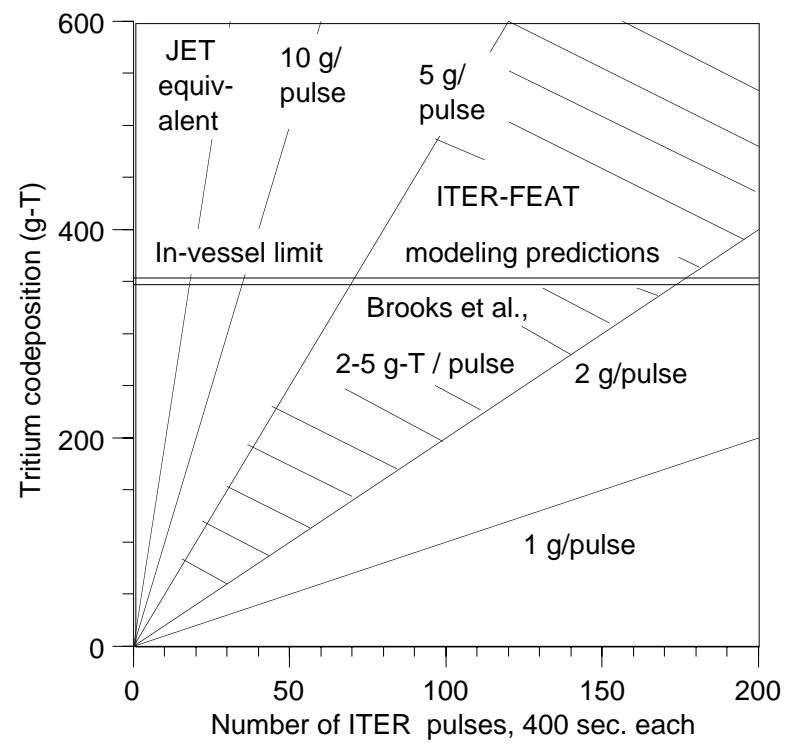

Fig.2 Tritium retention for ITER, showing modeling predictions[5] and JET DTE equivalent rate. The inventory limit (shown by double line) is predicted to be reached in approximately 100 pulses.

only 10-15 min of cumulative DT plasma operation. To address this concern, ITER will maintain the option to switch from CFC to $\mathrm{W}$ armour on the divertor targets prior to DT operation. This change will depend on the frequency and severity of ELMs and disruptions in the initial hydrogenic plasmas and the effectiveness of techniques to mitigate tritium codeposition.

FIRE is a next step option being designed in US, and is aimed at understanding and optimizing alpha dominated burning plasmas. While a smaller machine, the heat loads

Table 2 Comparison of FIRE and ITER parameters.

\begin{tabular}{rcc}
\hline & FIRE & ITER \\
\hline major radius, $\mathrm{R}$ & $2.14 \mathrm{~m}$ & $6.2 \mathrm{~m}$ \\
magnets & Liquid $\mathrm{N}_{2}$ cooled, $10 \mathrm{~T}$ & Superconducting, 5.3 T \\
fusion power & $150 \mathrm{MW}$ & $500+\mathrm{MW}$ \\
pulse duration & $\sim 20 \mathrm{~s}$ & $400 \mathrm{~s}$ \\
duty cycle & $0.2 \%$ & $10 \%$ \\
disruption energy on divertor & $4-96 \mathrm{MJ} / \mathrm{m}^{2}$ & $10-100 \mathrm{MJ} / \mathrm{m}^{2}$ \\
divertor material & $\mathrm{W}$ & $\mathrm{CFC}$ \\
divertor lifetime & $70-300$ disruptions & $-4000 \mathrm{pulses}$ \\
in-vessel T inventory limit & $15 \mathrm{~g}$ & $350 \mathrm{~g}$ \\
pulses before T removal & not an issue & $70-170 *$ \\
cost & $\approx \$ 1 \mathrm{billion}$ & $\approx \$ 5 \mathrm{billion}$ \\
\hline
\end{tabular}

\footnotetext{
* For a ITER W divertor, the lifetime would be similar to FIRE and $\mathrm{T}$ removal not an issue.
} 
on the FIRE divertor are similar to ITER because of the much higher fusion power density. FIRE plans to have a $\mathrm{Be}$ coated $\mathrm{Cu}$ wall and $\mathrm{W}$ divertor and no carbon plasma facing components[14]. W brush materials have been successfully tested at heat fluxes up to $25 \mathrm{MW} / \mathrm{m}^{2}$ however erosion and melt-layer loss during off normal events such as disruptions and ELMs are key issues for the lifetime of $\mathrm{W}$ clad divertor targets (Table 2). Techniques for mitigating or avoiding disruptions are under development. Since tungsten is a very efficient radiator and its core concentration must be less than $\left(\mathrm{n}_{\mathrm{i}} / \mathrm{n}_{\mathrm{e}}<10^{-5}\right)$ impurity influx must be severely limited. ASDEX Upgrade has shown encouraging results in this regard[15]. The major benefit of the absence of carbon is the very low tritium retention, which allows a major reduction in tritium inventory. The invessel tritium inventory limit for FIRE is only $15 \mathrm{~g}$ and allows FIRE to be classified in the U.S. as a Category III Low Hazard Nuclear Facility.

\section{TRITIUM IN IFE DESIGNS}

Many tritium issues in IFE are similar to those found in MFE[16]. For dry wall chamber designs such as Sombrero, codeposition of carbon and tritium is a concern along with deposition of target ablator materials. The extended boundaries associated with IFE beam tubes may make this deposition difficult to control. The target factory in IFE has no MFE equivalent. At present permeation is used to fill IFE targets and straightforward extrapolation of this technique could result in very large tritium inventories, however some innovative techniques such as non diffusive capsular fill and cryogenic assembly are being explored to reduce this. Fast ignitor target designs also offer prospects of reduced inventory. Robust confinement barriers for accident conditions may be $50 \mathrm{~m}$ up the beam lines[11] and control of such a large confinement boundary may be difficult. On the positive side the simpler geometry of IFE offers potential for higher tritium breeding ratios.

\section{DIAGNOSTIC NEEDS FOR MFE NEXT-STEP DEVICES}

There is significant uncertainty in predictions of tritium behaviour in next step devices, uncertainty that is much larger than predictions of core plasma performance. In view of the potential for loss of plasma operational time due to time spent on tritium removal there is an urgent need to address this. While sophisticated models are available to predict edge plasma behavior in tokamaks, there are typically many more adjustable parameters in the models than constraints due to experimental data. Agreement between observed deposition in JET and DIVIMP modeling was only achieved after including drift in the scrape off layer, additional interaction with the main chamber wall and enhanced erosion of the re-deposited carbon films at the inner target. Together, these altered deposition patterns in JET by more than an order of magnitude[17]. Carbon transport and tritium codeposition in the inner divertor/louver is under detailed analysis using the CARJET/REDEP, MOLDYN and ADAS codes with the goal of validating on JET the model used to predict tritium retention on ITER[18]. 
Diagnosis of the edge / wall region is difficult because of the lack of symmetry due to open flux surfaces intersecting plasma facing components. Understanding of the complex non-linear feedback between the plasma boundary and materials is limited by the available diagnostic information and low priority given to dedicated run time for plasma wall interaction studies[19]. Higher priority for divertor and wall diagnostics, is needed e.g. sensitive Langmuir probes, CXN measurements, IR camera, erosion / deposition collector probes, microbalances, laser desorption to measure $\mathrm{D} / \mathrm{C}$ ratio of hydrocarbon films, sticking probes, molecular spectroscopy together with dedicated run time for experiments on e.g. SOL drift with reversed grad B and thick Be wall coatings.

Two other diagnostic areas are highly relevant to next step needs. In-vessel dust can be highly reactive, for example, a loss of cooling accident may result a steam reaction with $\mathrm{Be}$ dust and the hydrogen generated can pose a detonation risk. There are strict regulatory limits on vessel dust for these reasons, however diagnostics to demonstrate compliance with these limits remain a major challenge[20]. As can be seen above, disruption erosion is a major driver in the choice of plasma facing materials and diagnostic advances to confidently identify disruption precursors would facilitate disruption mitigation and avoidance. More information on MFE diagnostic needs is given in ref. [19]. For diagnostic considerations for a large scale IFE facility we refer the reader to ref. [21].

\section{TRITIUM REMOVAL BY A SCANNING LASER}

Efficient and rapid tritium removal will be essential to future devices with carbon plasma facing components. Present candidate techniques involve oxidation of the codeposit at temperatures above $250 \mathrm{C}$ but raise several issues. The introduction of oxygen into a tokamak deconditions the walls and requires lengthy reconditioning to restore high performance plasma operations. It also raises issues of collateral damage on in-vessel components. The product of the oxidation is tritiated water that requires expensive reprocessing[3]. A further complication is that the temperature required is beyond the range of pressurized water cooling. However, to thermally desorb tritium it is not necessary to heat the whole vacuum vessel since most of the tritium is codeposited on the surface. The present method is based on surface heating with a scanning laser beam. Modeling showed that a laser power density of $3 \mathrm{kw} / \mathrm{cm}^{2}$ and heating duration of $20 \mathrm{~ms}$ could heat a 50 micron codeposit to $1000 \mathrm{C}-2000 \mathrm{C}$ appropriate for tritium release[22].

The laser scanning method for tritium release has been successfully tested on graphite and carbon fiber composite (CFC) tiles with tritiated codeposits from the TFTR DT campaign. The focussed beam from a continuous wave 325 watt Nd:yag laser was scanned in a raster pattern over the codeposited surface transiently heating it up to $1500-2000 \mathrm{C}$ for $10-200 \mathrm{~ms}$ releasing a major fraction of the tritium 23]. The surface temperature was measured by a pyrometer operating in the $1.58-1.8$ micron band, with a $0.7 \mathrm{~mm}$ measuring spot and response time of $0.3 \mathrm{~ms}$. Interestingly the temperature excursion of the codeposited layer was significantly higher than a bare graphite surface $(1770 \mathrm{C}$ compared to $1080 \mathrm{C})$, implying a very different thermal con- 


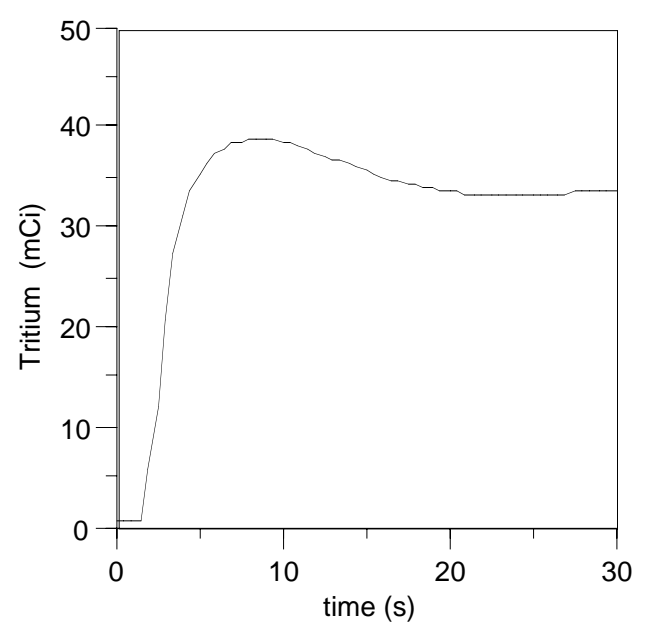

Fig.3 Tritium recorded by an ion chamber after laser irradiation. The delay is due to the pumping time.

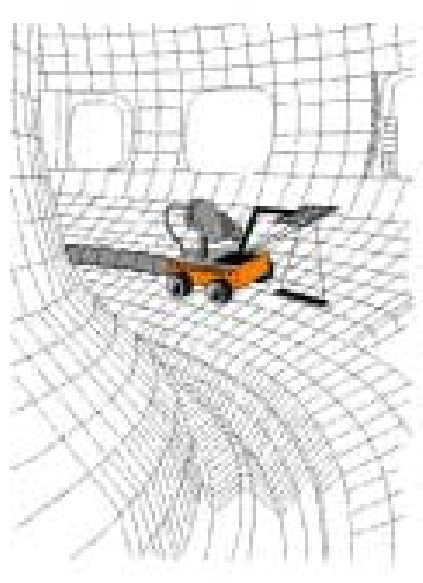

Fig.4 Potential implementation in a next step device.

ductivity. This underlines the importance of testing heat flux loads on tokamak generated codeposits.

The released tritium was measured by circulation in a closed loop system to an ion chamber (Fig.3). A movie of the laser in action may be seen on the web at ref. [24]. Microscopic images of the incandescence from the laser spot showed micro "hot spots" presumably due to the inhomogeneous granular structure of the codeposits. Any change in appearance of the codeposited layer was recorded with a microscope. While slow scans (>50 ms heat pulse) resulted in visible ablation of the surface, fast scans $(10-20 \mathrm{~ms})$ showed almost no change to the surface appearance, indicating that the release of tritium was not accompanied by ablation of the codeposit. Optimal conditions were laser intensity of $8 \mathrm{kw} / \mathrm{cm}^{2}$, scan speed $2 \mathrm{~m} / \mathrm{s}$ and local heating duration $10-20 \mathrm{~ms}$, resulting in surface temperatures $1300-2000 \mathrm{C}$.

Tritium remaining after the laser scan was released by heating with an unfocussed stationary laser spot in an air atmosphere for 30 minutes, which oxidised the remaining codeposit. Two experiments at different focal intensity showed a large fraction $(46 \%$ and $84 \%$ ) of the tritium released by the laser scan. This is an encouragingly high number and further optimization may be possible.

High power Nd lasers with fiberoptically coupled scanning heads are a proven technology in manufacturing. For a next step device we envisage a scaled up system with a multi-kilowatt laser beam delivered by fiberoptics on a robotic arm or mobile robot inside the vessel (fig.4). Energetically $30 \mathrm{MJ}$ are needed to heat the top 100 microns of a $50 \mathrm{~m}^{2}$ codeposited area from 400 to $2000 \mathrm{C}$ and this corresponds to the output of a $3 \mathrm{kw}$ laser for 3 hours. Clearly much work remains to be done to develop this technique at an engineering scale, however the initial results show clearly that tritium can be released by a scanning laser without the deleterious effects of oxidation. 


\section{ACKNOWLEDGEMENTS}

We acknowledge the invaluable contributions from our colleagues to this work, in particular C. Gentile, K. Young and the PPPL tritium group for the laser detritiation study and J. Brooks, J.P.Coad, D. Meade and M. Ulrickson. Support for the Nd laser work was provided by the Annex IV to the JAERI/DOE Implementing Arrangement on Cooperation in Fusion Research and Development, U.S. DOE Contract Nos. DE-AC0276CH0307. One of us (GF) acknowledges support from the ITER EDA Agreement.

\section{REFERENCES}

1. A. Gibson et. al., Phys. Plasmas, 5 (1998) 1839.

2. R. J. Hawryluk, Reviews of Modern Physics, 70, (1988) 537-587.

3. C. H. Skinner, et al., Nuclear Fusion 39 (1999) 271.

4. G. Federici, C. H. Skinner et al., "Plasma-material Interactions in Current Tokamaks and their Implications for Next-step Fusion Reactors", PPPL-3531/IPP-9/128 January 2001, http://www.pppl.gov/cgi-bin/pubrepcpyreq_2001.pl Nuclear Fusion in press.

5. G. Federici et al., J. Nucl. Mater., 290-293 (2001) 260.

6. C. H. Skinner, et al., J. Nucl. Mater. 290-293 (2001) 486.

7. P. Andrew et al., Fusion Eng.\& Des. 47 (1999) 233.

8. C. H. Skinner et al., "Long Term Tritium Trapping in TFTR and JET" Proceedings of the $28^{\text {th }}$ EPS Con ference on Controlled Fusion and Plasma Physics, Madeira, Portugal, 18-22 ${ }^{\text {nd }} J u n e, 2001$.

9. W.R. Wampler, et al, "Long Term Retention of Deuterium and Tritium in Alcator C-mod" Proceedings of the 18th IEEE/NPSS Symposium on Fusion EngineeringAlbuquerque, October 6-10, 1999, p.267 IEEE, Piscataway, NJ, USA (1999).

10. R P Crease, "True Tritium Tales" Physics World, August 2001 p.18.

11. D. Petti, "Tritium Safety Issues" ARIES Town Meeting on Tritium and the DT Fuel Cycle March 6,7, Livermore CA. http://michelle.ucsd.edu/LIB/MEETINGS/0103-ARIES-TTM/

12. L. El-Guebaly, "Tritium Breeding Issues for MFE and IFE" ARIES Town Meeting on Tritium and the DT Fuel Cycle March 6,7, Livermore CA. http://michelle.ucsd.edu/LIB/MEETINGS/0103-ARIESTTM/

13. G. Federici et al., Physica Scripta T91 (2001) 76.

14. M. A. Ulricksen et al., Fusion Technology 39 (2): 378-382, Part 2 MAR 2001

15. R. Neu et al., J. Nucl. Mater., 290-293 (2001) 206.

16. K. Schultz et al., "Meeting Summary Session 2" ARIES Town Meeting on Tritium and the DT Fuel Cycle March 6,7, Livermore CA. http://michelle.ucsd.edu/LIB/MEETINGS/0103-ARIES-TTM/

17. J. P. Coad et al., J. Nucl. Mater., 290-293 (2001) 225.

18. J. N. Brooks et al., personal communication.

19. G.F. Counsell et al., J. Nucl. Mater., 290-293, (2001) 255.

20 G.T. Razdobarin, et al., J. Fusion Science and Technology (in press).

21. P. Bell et al., Rev. Sci. Instrum., 72 (2001) 492.

22. C. H. Skinner et al., Proceedings of the $17^{\text {th }}$ IEEE/NPSS Symposium Fusion Engineering, San Diego, Ca. Oct 6-10, 1997, p.321.

23. C.H. Skinner et al., "Tritium removal from codeposits on carbon tiles by a scanning laser" Report \# PPPL3603 (Sept. 2001) 29pp, submitted to J. Nucl. Mater. 2001 http://www.pppl.gov/pub_report/.

24. http://www.pppl.gov/tritium/page11.html 


\section{External Distribution}

Plasma Research Laboratory, Australian National University, Australia

Professor I.R. J ones, Flinders University, Australia

Professor J oão Canalle, Instituto de Fisica DEQ/IF - UERJ , Brazil

Mr. Gerson O. Ludwig, Instituto Nacional de Pesquisas, Brazil

Dr. P.H. Sakanaka, Instituto Fisica, Brazil

The Librarian, Culham Laboratory, England

Library, R61, Rutherford Appleton Laboratory, England

Mrs. S.A. Hutchinson, JET Library, England

Professor M.N. Bussac, Ecole Polytechnique, France

Librarian, Max-Planck-Institut für Plasmaphysik, Germany

J olan Moldvai, Reports Library, MTA KFKI-ATKI, Hungary

Dr. P. Kaw, Institute for Plasma Research, India

Ms. P.J . Pathak, Librarian, Insitute for Plasma Research, India

Ms. Clelia De Palo, Associazione EURATOM-ENEA, I taly

Dr. G. Grosso, Instituto di Fisica del Plasma, Italy

Librarian, Naka Fusion Research Establishment, J AERI, J apan

Library, Plasma Physics Laboratory, Kyoto University, J apan

Research Information Center, National Institute for Fusion Science, J apan

Dr. O. Mitarai, Kyushu Tokai University, J apan

Library, Academia Sinica, Institute of Plasma Physics, People's Republic of China

Shih-Tung Tsai, Institute of Physics, Chinese Academy of Sciences, People's Republic of China

Dr. S. Mirnov, TRINITI, Troitsk, Russian Federation, Russia

Dr. V.S. Strelkov, Kurchatov Institute, Russian Federation, Russia

Professor Peter Lukac, Katedra Fyziky Plazmy MFF UK, Mlynska dolina F-2, Komenskeho Univerzita, SK-842 15 Bratislava, Slovakia

Dr. G.S. Lee, Korea Basic Science Institute, South Korea

Mr. Dennis Bruggink, Fusion Library, University of Wisconsin, USA

Institute for Plasma Research, University of Maryland, USA

Librarian, Fusion Energy Division, Oak Ridge National Laboratory, USA

Librarian, Institute of Fusion Studies, University of Texas, USA

Librarian, Magnetic Fusion Program, Lawrence Livermore National Laboratory, USA

Library, General Atomics, USA

Plasma Physics Group, Fusion Energy Research Program, University of California at San Diego, USA

Plasma Physics Library, Columbia University, USA

Alkesh Punjabi, Center for Fusion Research and Training, Hampton University, USA

Dr. W.M. Stacey, Fusion Research Center, Georgia Institute of Technology, USA

Dr. J ohn Willis, U.S. Department of Energy, Office of Fusion Energy Sciences, USA

Mr. Paul H. Wright, Indianapolis, Indiana, USA 
The Princeton Plasma Physics Laboratory is operated by Princeton University under contract with the U.S. Department of Energy.

\author{
Information Services \\ Princeton Plasma Physics Laboratory \\ P.O. Box 451 \\ Princeton, NJ 08543
}

Phone: 609-243-2750

Fax: 609-243-2751

e-mail: pppl_info@pppl.gov

Internet Address: http://www.pppl.gov 